\title{
Preparation for an uncertain world: professional agency and durability in the practice preparation of mental health in occupational therapy
}

\author{
Katherine Wimpenny, PhD, MSc, DipCOT, PGCert HE. \\ Senior Research Fellow, Disruptive Media Learning Lab, Coventry University, UK
}

Loren Lewis, BSc O T (UCT)

Clinical Educator. Division of Occupational Therapy, Faculty of Health Sciences, University of Cape Town

Introduction: This article presents the findings from a cross contextual pilot study, which investigated how the occupational therapy pre-registration programme prepares occupational therapy graduates for contemporary mental health practice. In particular occupational therapy graduates in their first post were asked for their perspectives about how the curriculum had equipped them to be visible, agented and influential therapists, fit for practice for contemporary mental health.

Method: Using case study methodology, II graduates from a South African and a UK university were interviewed and the data thematically analysed and interpreted.

Findings / Results: Four key themes are presented, namely: 'identity and relationship to the profession'; 'informing personal attributes and characteristics'; 'professional knowledge and knowing'; and 'capacity, desire and durability to be, do, and act in practice'.

Conclusion: The findings revealed that the challenge for professional education in occupational therapy mental health lies in developing graduates as agented therapists with a strong professional identity and ability to creatively implement occupation-focused practice. Moreover, graduates need to be durable therapists, equipped in promoting professional perspectives amidst complex multi-agency organisational dynamics in the changing environment of practice.

Key words: education, mental health, graduate, practice

\section{INTRODUCTION}

There are drastic changes occurring within the context of occupational therapy practice which are challenging the profession to examine its 'validity, effectiveness, professional values, ethics and motivations'. Such challenges are evident within mental health occupational therapy practice. Suggested reasons for such a precarious positioning in the mental health service sector include insufficient advocacy for the profession's role coupled with an inability to flexibly embrace health care changes during de-institutionalisation and the transition of services into community provision ${ }^{2}$. Furthermore, policies and nosologies such as the International Classification of Health, Functioning and Disability ${ }^{3}$, the United Nations Convention of the Rights of People with Disabilities ${ }^{4}$, and most recently, the fifth edition of the Diagnostic and Statistical Manual of the Mental Disorders (APA, 20I4) , $^{5}$ are re-aligning the ambit of practice domains. By foregrounding the social determinants of health, these and other direction-determining documents are de-constructing the medical model of illness and disability and precipitating the need for considerable curriculum reform.

In the United Kingdom, recent health service policies are calling for practice based evidence arising from community centred intervention ${ }^{6,7,8,9}$. With loss of posts and insufficient research capturing the effectiveness of occupational therapy services in mental health ${ }^{10}$ the profession must convince service commissioners of the relevancy of occupational therapy services as a key element in the community integration for people with mental illness.

From the South African perspective, the National Development Plan (NDP)" , the proposed National Health Insurance scheme, as well as the re-engineering of Primary Health Care $(\mathrm{PHC})^{12}$ has necessitated changes to healthcare delivery, all of which are influencing the way in which health professionals, including occupational therapists are able and needing to practise. These policy directives aim, amongst others, to eliminate poverty, reduce inequality and improve the health and well-being of the population by 2030 . While the overarching objectives of policy reform are philosophically embraced by occupational therapy, the profession has to ensure its curriculum equips practitioners with the requisite knowledge and skills to work differently in a rapidly and constantly changing service arena. Within mental health, focus has shifted to prevention and promotion ${ }^{13}$ and the establishment of community based services integrated into PHC. However, government investment into mental health human resources and infrastructure is required on a 'massive scale'14 and this is slow to materialise. The lack of resources to support community-based mental health care currently results in the well documented revolving-door phenomenon as well as prevalent mental illnesses going undetected. The challenge is to train practitioners with a skill set that can interrupt the revolving door while simultaneously addressing the social determinants of mental ill health and ill-being. Occupational therapy graduates need to have the necessary skills to be proficient therapists working in these complex and expanding practice domains. Pattison ${ }^{15}$ recommends that undergraduates be offered the opportunity to explore a globalised picture of mental health occupational therapy practice through the use of pedagogy designed to encourage students to think creatively, engage in individual and group problem solving, develop innovative ways to deliver culturally-sensitive services, to discuss strategies, take calculated risks and consider ways and means of extending the reach of the profession.

This paper presents the findings from a pilot study involving graduate occupational therapists from the United Kingdom (UK) and South Africa (SA), working in their first mental health post, to explore their perspectives about how the pre-registration cur- 
riculum equipped them to work within mental health practice. An Applied Research Fellowship awarded to the first author enabled the North-South research collaboration to occur. As occupational therapy educators and researchers we were interested to examine what we could learn from one another's distinct programme and practice settings. The following research aim was explored:

To investigate graduates perspectives about what, in their experience of the occupational therapy curriculum, has equipped them to be visible and influential therapists, fit for practice for contemporary mental health.

\section{BACKGROUND LITERATURE}

Bannigan et al ${ }^{16}$ asserted that the UK mental health occupational therapy graduate was not prepared adequately to work in the mental health sector following registration. Proceeding debate within the professional literature focussed on the occupational therapy pre-registration curriculum; key areas of contention focussed on the mental health component and the importance of professional core skills $s^{9,17,18}$.

Professional insecurity and role uncertainty experienced by occupational therapists working in mental health have been well documented over the past decade $20,21,22,23,24,25,26$. Reasons for this uncertainty are varied, yet tend to be linked to the fact that the scope of our practice is both broad and individualistic. It is evident that the profession needs to justify its existence and prove its value $^{24,25,27,28}$. An inability to project an accurate professional role results in neither the provider units nor consumers of occupational therapy services being able to make a reasoned argument regarding the need for, or development of, occupational therapy staff and facilities.

The scope of mental health occupational therapy practice both in the UK and SA context continues to change and it makes sense that parallel changes in mental health education take place. Contemporary practice is a fluid, challenging responsibility, which requires practitioners to work with heavy caseloads, in complex situations often of an indeterminate nature ${ }^{29}$. Practitioners need to develop capacity to be knowledgeable about their specific contribution and to make explicit their professional understandings ${ }^{26,29}$.

With the shift in focus to Primary Health Care (PHC) within the SA domain, the challenge lies in adapting the curriculum in order to prepare occupational therapy graduates to work within this approach. Graduates need to complete a year of community service training in their first year of practice. During this period graduates may have to cope with limited supervision from experienced clinicians in rural or under-privileged areas. In rural areas there may be no existing rehabilitative services or an absence of $\mathrm{PHC}$ implementation.

Graduates in the UK similarly are faced with promoting professional perspectives. An area of significant tension revolves around practitioners' adoption of generic skills for broad-spectrum mental health working whilst striving to maintain an element of profession-specific practice. This has been most notably experienced within community mental health teams where consensus regarding the optimal type of casework for occupational therapists has not been reached ${ }^{26,30}$. Consequently graduates need to project a strong professional identity, demonstrate skills in evidence-based practice, critical thinking and resilience ${ }^{31,32}$. Further, the accepted understanding of the role of occupational therapy practice must be widened to encompass the diversity of what the profession has to offer ${ }^{33}$.

Whilst there has been little focus on mental health occupational therapy practice preparation, a number of studies have taken a broader curriculum view ${ }^{31,34,35,36,37,38,39}$. Such studies, whilst addressing a range of practice and education themes, typically reveal that new graduates grapple with low confidence when entering the working world ${ }^{31}$. They have difficulty making the shift from student to graduate and the need for support structures to be put in place is evident ${ }^{36}$. Further, graduates have reported feeling inadequately prepared in the area of practical techniques and experience a large gap between their own perceived level of competence and perceived unrealistic expectations of themselves ${ }^{31}$. It is evident that it takes time for graduates to feel competent and gain professional confidence, including clarifying their professional role, and being clear of their responsibility when working within a team.

Graduates rely heavily on theory to guide their practice and their interactions with other members of the multi-disciplinary team ${ }^{31,38}$. While practice education was seen to be the most beneficial aspect of the curriculum in preparing graduates for practice, the literature points to improved educational strategies to integrate theory into practice $^{38}$.

With this backdrop in mind, this study sought to explore graduates' perspectives about how the occupational therapy curriculum for mental health had prepared them for their practice.

\section{METHODOLOGY AND METHODS}

Case study methodology was used to address the research question as it provided opportunity to develop greater understanding of a case $^{40}$; the case being a "specific, complex, functioning thing" $41: 2$. Graduate preparedness for practice was viewed as the case, however differences in institutional, student and societal demographics and distinction between the UK and SA policy environments were taken into account.

The chosen methodology was framed within social constructionism, from this theoretical perspective, whilst individuals are seen as engaging in their world and making sense of it, individual's perspectives and experiences are viewed in the context of history, social perspective and the political sphere ${ }^{42}$. Thus social constructionism was principally concerned with examining the respective socio-cultural-political-educational environments and the processes by which the graduates would describe, explain or otherwise account for their practice and their 'world'.

\section{Ethics}

Ethical approval was granted from each institution. This required that; the rights and opinions of those involved in the study were respected (e.g. through participant validation and member checking); the research participants involvement was voluntary, free from coercion; harm to participants was avoided; any conflict of interest was made explicit; research participants were informed about possible risk and quality was assured through researcher reflexivity and trustworthiness.

\section{Sampling}

Convenience sampling was utilised in this study. A sample population of graduates from a SA University was recruited following a presentation about the research proposal delivered on campus by the first author prior to the graduates starting their one year community service post. Graduates who were willing to be involved in the research project provided the first author with their contact details after the presentation $(n=6)$. Band 5 (equivalent) graduates from a UK university were contacted through the University's Practice Education Co-ordinators Network $(n=6)$. All graduates that made contact with the first author, were sent Participant Information Sheets, and provided their consent.

Table I on page 24 provides the (anonymised) details of the graduates including their gender, age and first post setting. The SA and UK groups represent differences mainly in terms of age. Several of the UK graduates had studied through in-service routes (such students complete their studies part time whilst working as occupational therapy assistants / support workers).

\section{DATA COLLECTION}

Questions for interviews were developed from themes from a documentary analysis of the respective University course documents (the focus of a separate paper). The questions asked were the same for the two different graduate populations. Example questions are provided in Table II. 
Table I: Profile of UK and SA graduates

\begin{tabular}{|l|c|c|c|c|c|}
\hline Graduate name & Context & Programme & Gender & Age range & First post setting \\
\hline Shamila & SA & $4 \mathrm{yr}$ (full time) & F & $20-25$ & Rural hospital \\
\hline Nicky & SA & $4 \mathrm{yr}$ (full time) & F & $20-25$ & Psychiatric hospital \\
\hline Celeste & SA & $4 \mathrm{yr}$ (full time) & F & $20-25$ & Rural hospital \\
\hline Sybrand & SA & $4 \mathrm{yr}$ (full time) & F & $20-25$ & Psychiatric hospital (forensic) \\
\hline Tara & SA & $4 \mathrm{yr}$ (full time) & F & $20-25$ & TB hospital \\
\hline Leah & SA & $4 \mathrm{yr}$ (full time) & F & $20-25$ & Rural hospital \\
\hline Sam & UK & 4 yr (in-service route) $)^{1[l]}$ & F & $25-35$ & Community Mental Health Team (CMHT) - Crisis team \\
\hline John & UK & $3 \mathrm{yr}$ (full time) & M & $30-40$ & Employment Rehab \\
\hline Andrea & UK & 3 yr (full time) & F & $20-25$ & Acute rehab (Male) \\
\hline Sally & UK & 3 yr (full time) & F & $20-25$ & Acute hospital \\
\hline Peter & UK & In-service route & M & $30-40$ & Forensic Medium secure (male) \\
\hline Dawn & UK & in-service route & F & $30-40$ & Community Mental Health Team \\
\hline
\end{tabular}

Table II: Example interview questions

\begin{tabular}{|l|}
\hline I. What is your current role? \\
\hline 2. Was this a new post for occupational therapy or had the service previously employed occupational therapists? \\
\hline 3. What module(s) have you found helpful, or valuable in equipping you for your current work (as an occupational therapist) in mental health? \\
\hline a. Ask for an example of a specific module \\
\hline b. Delivery methods \\
\hline c. Study regime \\
\hline d. Assessment \\
\hline e. Learning outcomes achieved \\
f. Feedback received on performance \\
\hline 4. In what ways did your professional training help prepare you for practice in mental health and in what ways did it not? \\
\hline 5. What do you find challenging in your job? \\
\hline 6. What in your job gives you the greatest satisfaction
\end{tabular}

Semi-structured interviews were conducted face to face by the first author with all the UK graduates located in hospital and community mental health settings. Two semi-structured interviews were conducted face-to-face by the second author with graduates working within the Western Cape, SA $(n=2)$. One Skype and one telephone interview were conducted by the first author for graduates in rural locations across Southern Africa. Due to technical issues one graduate responded to the question areas in writing. One graduate did not maintain contact, despite the team's best attempts to ascertain any technical or communication problems as barriers.

\section{Analysis}

A total of I I interviews were transcribed verbatim and analysed collaboratively by the first and second authors using thematic analysis ${ }^{43}$. As the authors were working in different contexts, key words were defined and discussed throughout to support how the meaning of a word or phrase could be understood. Whilst the analysis did not utilise a priori codes, a focus for the analysis was how the data sets revealed graduate perspectives about their occupational therapy preparation and practice within the mental health arena. The analytic process involved a progression from description, where the data were organised to show patterns in content, and summarised, to interpretation, to where themes were developed, illustrating the significance of the patterns and their broader meanings and implications. This required an iterative process of reading, re-reading, preliminary coding and generation of themes and their subthemes. The themed areas captured something important about the data in relation to the research question, and represented some level of patterned response or meaning within the data set. The researchers kept reflective notes, highlighting connections and differences between the themes and their subthemes.

Themes were defined and contextualised with data evidence. Whilst initially analysed as two separate case studies, the graduates' views were brought together as one case due to the overlap of themes.

Situated within a social constructionist framework, the analysis process focused on the socio-cultural contexts that supported the individual accounts that are provided.

\section{Trustworthiness}

Researcher reflexivity, peer evaluation, maintaining data integrity and being explicit about researcher stance and the research methods employed were key strategies used to maintain trustworthiness.

\section{FINDINGS}

The findings are presented in four overarching themes;

I. Identity and relationship to the profession

2. Informing personal attributes and characteristics

3. Professional knowledge and knowing

4. Capacity, desire and durability to be, do, and act in practice Each theme is presented below.

\section{Identity and relationship to the profession}

The importance of professional positioning with respect to defining ones' identity and role emerged as a strong theme amongst the graduates.

For example, this was revealed when a UK graduate shared his experience of being the only occupational therapist affiliated to a ward, it was his role to think about how he could shape that 
ward to promote occupational therapy practice. He advocated for his role in saying, "look we need an OT in this area because these are the things we can do".

Finding their feet and negotiating their role within the multidisciplinary team was evident in this graduate's reflection:

"sort of finding myself in this role but there's lots of things l'd like to do here...other people you work with don't have the same vision as you, maybe you're too excited, a bit too fresh....that can sort of dampen, or get to you." (SA graduate)

A confidence and willingness to promote and enact professional perspectives for mental health practice was evident across the data. Graduates demonstrated their enthusiasm in promoting occupational therapy services:

"OT's are getting the word out that you can have a better life, raising awareness... you know that you can do more for yourself than you actually believed before." (SA graduate)

The graduates spoke of how their professional identity was explored through the curriculum from day one, through the importance of effective communication within therapeutic relationships; the core concept of occupation for health, and the influence of context on wellbeing. Further, it was evident that both university programmes placed high importance and value on enhancing reflective skills. This was achieved by creating regular opportunities for reflection and developing students' ability to think critically about personal and professional perspectives, as highlighted in the graduate's response below:

"There were lots of readings which we would do in our own time, and then we would be asked questions about this in class and have to reflect by ourselves and as a group regularly." (SA graduate)

These 'touch points' on the programme, prompted in-depth reflection about the potential of mental health and wellbeing through occupation, and inadvertently encouraged the graduates to explore their role identity.

2. Informing personal attributes, dispositions and characteristics

This theme illustrates how the graduates, through their personal capacities, dispositions and characteristics, supported clients to consider meaningful ways to move forwards in their recovery in a profound way:

"I think my compassion and drive to want to help others is a great benefit to me in my role as an OT. I am not an OT to lead a life of the rich, but to enrich the life of others." (SA graduate)

The relationship between the graduates' worldview and respect for people coupled with professional ideas and philosophies were clearly illustrated. Graduates spoke of the programme validating their own previously held beliefs and values. For some, it seemed difficult to separate the university knowledge from the knowledge they had acquired leading to their training (especially for mature students on in-service routes). What was evident, however, was the graduates' compassion and motivation to support people to manage their required and desired occupational needs, illustrated through graduates' genuine desire to contribute:

"Working with people is important to me, and having a job that I could make a difference in people's lives and bring meaning." (UK graduate)

It was evident that graduates were able to further experience how the profession served to enable mental wellbeing, through their own experience of engaging in occupation. Graduates shared how their personal experience led to their aspirations of wanting to utilise the 'power of occupation' with others in practice.

Alongside personal attributes informing professional perspectives, all the graduates appreciated the contribution of their training in enabling them to further understand and enact their discipline.

\section{Professional knowledge and knowing}

In terms of an informing pedagogy it was evident that all the graduates had been encouraged to be self-directed learners from the outset:

"You have to be autonomous with the way you work; you need to have that sense of autonomy when you're working. You need to be able to go away as a student and find things out for yourself." (UK graduate)

Further, the use of lectures, (guided) reading, seminars, tutorials and workshops, enabled material to be explored, discussed and challenged. For example, creating spaces for reflection in the curriculum were a key aspect that developed this core skill and further enabled the development of graduates' clinical reasoning.

Graduates were appreciative that the curriculum could not cover content to account for all eventualities. Rather, graduates identified with particular 'frameworks for thinking' which they drew upon to support them in their practice. This theme identifies with the types of propositional, practical and experiential forms of knowing recognised as being of particular significance. The reflection and action cycle being a core framework for one SA graduate as illustrated below:

"[The] action, reflection, learning cycle, has saved my soul because it makes me think about my sessions and how they could have gone better ... [the] cycle gives it a structure, how to think about it... I've got a way to formulate my thoughts"

This learning cycle provided this graduate with a means of critiquing her mental health practice competence, whilst clinical reasoning frameworks were used to help figure out what to do, how to do it and to explain why.

Other frameworks of knowing included the principles of person-centred and holistic practice, the value of understanding mental health conditions, handling techniques, the contribution of occupational science and conceptual practice models, human development and equity and diversity studies:

"I think the theory, definitely mental health theory, occupational justice theory and occupational theory in general, I think that sort of flames your thinking, and you don't actually realise, but it sort of becomes a part of you, with regards to how you reason things." (SA graduate)

Although the understanding of professional theory and reasoning was not immediately evident - Occupational therapy theory was very 'out there' and 'wishy washy', I remember thinking 'what is this?!" (SA graduate) - On completing the programme, it was appreciated how such knowledge supported the enactment of practice. The process of making sense of propositional knowledge was enabled through the practical learning elements that graduates were exposed to on their various mental health placements. Graduates described this aspect of the programme as being invaluable. Practice learning was seen as the key factor in preparing graduates for their first post or community service year. Most graduates made reference to falling back on, and applying learning experiences to scenarios that they were currently faced with, as illustrated below:

"The practice learning elements of the course were very, very, very important in equipping me for my community service, and for me $I$ know I learn better practically than just learning through theory, so while I know the theory and I learnt it, the practical skills learning come back instantly to support me." (SA graduate)

As well as practice learning, the focus on practical learning per se was a key component of professional knowing. Graduates spoke of consolidating their understanding of coursework through having to present, engage in role play and perform 
skills practice in front of peers and practitioners. The integration of theory and practice was also enabled through group work which provided a reserve of intervention strategies from which the graduates drew when managing specific issues in practice:

"I learnt loads [from group work] like playing out the skills which have fed perfectly into the experiences I have had here. They [the tutors] encouraged us to look into the condition of the person for the case study and then we looked at different interventions you'd do with them. And because you get to view everyone else's practical demonstrations, you learn loads because you see what everyone else has done. So that practical side is really important. If we'd have just read from a book or if they'd done it in a, like, lecturing type of style, I don't think it would have been as valuable to me as it was having all those practical experiences." (UK graduate)

The emphasis placed on shared learning in seminars and tutorials nurtured graduates' critical thinking and ideas about risk taking. The lecturers' approach was crucial in encouraging students to think for themselves, best described by the old proverb of 'give a man a fish and you feed him for a day. Teach a man to fish and you feed him for a lifetime.' The rod almost becomes part of the exit competency that is expected on graduating. The importance of lecturers' approaches towards learning material was a key contributor to 'thinking and knowing,' as illustrated below:

"It felt more like we were working together and learning together and academic staff not having all the answers and it felt quite safe that you could go with something that you hadn't done before. He was brilliant. And he made it feel like, that he would have enough experience himself that he'd be able to help you out if you became stuck. So, he gave us a lot of encouragement in that way to feel safe in making that choice." (UK graduate)

What is illustrated here is that equipping graduates for the challenge of mental health practice relies on drawing on frameworks and strategies which enable graduates to problem solve for themselves, to accept risk, to think critically, and have confidence to manage uncertainty in their professional positioning. How graduates handled practice situations is discussed in more depth in the final theme.

4. Capacity, desire and durability to be, do and act in practice

This theme explores how graduates made sense of their professional role identity in practice and how they enacted their disciplinary positions. The graduates spoke about how influential and visible they were across the diverse settings in which they were placed. They also identified areas they found challenging, which provided insight into areas where the curriculum fell short, or was too idealistic in preparing graduates for an uncertain world. For example the SA graduate below spoke of her work in a rural hospital setting:

"Well in the isiZulu language there isn't a real word for occupational therapy-it's 'Udokotela Wesingane', which translates to the 'Doctor of Children', so I think that's quite hard for adult patients or people in the community to understand the role of our therapy."

Not only did this graduate need to negotiate language barriers, a particularly complex issue in rural community settings, but also the creativity she required when working with finite resources:

"We have to be creative in thinking about what resources they have at home, as these are very different to the resources we have in urban homes. So for example, with children we would use rolled up grass mats that they make, for balancing games or wooden stumps for leap-frog."

Resource issues were of concern for both UK and SA graduates, nonetheless all graduates spoke of experiencing satisfaction in realising the impact their role could have. Graduates were required to manage staff dynamics by maintaining visibility in promoting disciplinary perspectives within a multi-disciplinary team. In doing so they revealed their commitment to their roles and to the people and communities they believed would benefit from accessing occupational therapy services:

"I'm not just coming from my pre-degree head where I thought it was unjust. I'm actually able to say why we shouldn't accept it or, you know, fight for that person as an individual." (UK graduate)

Yet equally, there was evidence of graduates feeling overwhelmed, with implied connotations that the curricula had fallen short in adequately equipping them for certain situations. For example, at the amount of responsibility graduates could quickly accrue, not only with regard to managing a heavy caseload, but also, in having responsibility to mentor or supervise other staff:

"One of the biggest challenges l've found is people management and managing activity workers and that level of responsibility that you feel once you're qualified. Suddenly you're in charge of people and knowing the general admin and sorting money out with budgets for the ward... I wasn't prepared for that change." (UK graduate)

As such, graduates spoke about the ways in which the curriculum could be improved:

"I honestly feel it would have been good to think more about all the potential challenges of working in a rural placement... working here is so different from practice learning contexts about working in a school, or a major hospital or even a clinic in the township areas, and I do think that opportunity to focus on such issues can help play a major role in the service you provide and the therapy you provide." (SA graduate)

Graduates suggested that the use of simulation in training might be one method of better equipping them for practice with "mock clinical team meetings, where you got people to rotate the roles and to reflect on what that felt like". (UK graduate) It is interesting that for the majority of graduates, the main area for curriculum development related to 'handling skills', and not necessarily for work with clients, but more so in terms of managing multidisciplinary team dynamics; in particular, through confidently reasoning one's professional perspectives, and through organisational politics. For example, in establishing occupational therapy services where none exist; findings which are supported in other studies examining graduate transition ${ }^{44,45}$.

\section{DISCUSSION}

Our findings from this preliminary study demonstrate that, in spite of the distinctions between the UK and SA contexts, a shared identity, shared socialisation processes and similar problems were revealed. These were most obviously demonstrated through graduates' questioning of their ongoing capacity to be a part of the mental health practice community in an authentic way.

It is widely recognised that commencing practice as an occupational therapist is a time of great professional development ${ }^{39}$, coupled with a sense of being overwhelmed ${ }^{37}$. Graduates need to be adaptable and flexible to change in order to successfully transfer into the world of professional practice. This is especially of note when considering the task graduates have in promoting the relevancy of occupational therapy as a key element of services for people with mental illness.

In considering how well the curriculum equipped them for mental health practice, the contribution of propositional knowledge (professional theory, professional constructs, philosophical underpinnings) as well as the importance of process and ways of 
acting in the world (disciplinary values, reserves of strategies for practical implementation, the influence of academic staff) were of particular note. It was evident that the emphasis on transformative education in the SA curriculum and that of enquiry-led learning in the UK curriculum supported the graduates' socialisation into the profession. The graduates spoke of entering professional life with a good sense of professional identity and an overwhelming desire to make a difference. Their confidence in the power of occupation motivated them to seek opportunities and promote suggestions for improvement, for the benefit of individuals and groups. It was also evident that graduates personal qualities, their drive and desire to transform the lives of others, despite feeling overwhelmed and frustrated, demonstrated a willingness to endure and to use personal resources to deal with stress. In thinking about disposition and qualities, one has to question whether the programme stimulated this way of thinking, or whether in fact the graduates already embodied this in their personal attributes and character that they brought to their studies.

The 'will' to be a professional is not only a matter of past formation, but is an abiding presence in being, and continuing to be, a professional. Barnett ${ }^{46}$ noted that professional life may hinder professional will through systems that reduce professional autonomy. Professional staff may have unique responsibilities but often with reduced power. An abiding presence therefore in being and continuing to be a professional is the willingness of professions to endure ${ }^{46}$. The role of education is to form graduates as professionals who will be enterprising in such a way that they will also be durable, through professional education which can be adequately responsive.

The concept of a 'responsive curriculum' can be understood as the pedagogical design and delivery of teaching and learning approaches that seek to promote the growth and transformation of learners and the profession through socially appropriate activities ${ }^{47}$. Knowledge frameworks that are contextually situated and responsive to the needs of communities where people live, work, learn and play are being developed and warrant curriculum inclusion ${ }^{48,49}$. Further, preparing graduates for an uncertain world requires a curriculum that is willing to manage uncertainties ${ }^{50}$. A curriculum whose pedagogy embraces open, negotiated and flexible learning intentions, including recognition of the risks associated with such approaches ${ }^{51}$. A curriculum which maintains the excitement about the philosophy of life that our profession offers and which can prepare graduates to:

I. Take risks, see and make use of opportunities to extend our professional reach within the mental health arena (drawing on theory and conceptual practice models, philosophical underpinnings, personal and professional commitment, creativity, problem solving)

2. Demonstrate professional agency and competence with the people with whom we work and serve (drawing on core knowledge frameworks of critical occupational analysis, critical self-reflection, and effective communication)

3. Be visible and influential with others, and in the delivery of effective practices with a necessary understanding of professional discourse for contemporary mental health practice (drawing on evidence based practice, professional agency, social responsibility and accountability) to challenge and broaden the scope and reach of occupational therapy in mental health.

\section{Implications for educational preparation for contemporary mental health practice and future research}

There is a pressing need to prepare occupational therapists to work in mental health.

Similar to Hoggets et $a^{11: 157}$ study, the graduates who participated in this pilot reported that they understood that there is no 'cookbook' for occupational therapy. Nonetheless, the graduates expressed a need for more guidance with regards to managing workplace dynamics including working with multi-agency colleagues who may be reticent to take on graduate perspectives. Whilst it is appreciated that graduates typically enter hierarchical systems in practice settings, a particular concern is how graduates are able to project their professional perspectives when they are the only representative for occupational therapy.

Further research is required to determine how the curriculum can prepare graduates to take on the challenge of working with colleagues when perspectives and assumptions differ, and to explore strategies for breaking down barriers which stifle and restrict what occupational therapy can achieve. This includes how the educational experience prepares graduates to contain, support, seek change and manage political and professional structures to enhance the mental wellbeing of individual, groups and communities through occupation.

This small-scale pilot study has highlighted that more needs to be known about the basis of the formation of professional durability; to work within diverse contexts rife with organisational politics and dynamics, and how these qualities are nurtured within professional education. Undergraduates need opportunities to be exposed to the intricacies of what they have to face in their community service or first practice post.

\section{CONCLUSION}

The findings of this pilot study revealed that the challenge for occupational therapy mental health education lies in developing graduates not only as professional staff fit for practice, but also fit for the changing environment of practice.

More needs to be understood about how best to prepare graduates with strategies and skills to promote professional visibility and be responsive to opportunities to extend professional reach in mental health. Significantly, the graduates in this study revealed that more opportunity is needed within the curriculum to embrace uncertainty, consider risk and organisational challenge, and replace feelings of doubt and insecurity with improved agency, in order to be able to manage the 'not knowing', to tolerate complexity, and be resilient.

\section{ACKNOWLEDGEMENTS}

Sincere thanks go to all the graduates who were involved in this study.

Thanks also go to Professor Madeleine Duncan for her advice and support and Liesl Peters for reviewing this article before submission.

\section{REFERENCES}

I. Fidler GS. The challenge of change to occupational therapy practice. Occup Ther Ment Health, 199I; II (I): I - II.

2. Gutman SA. Special issue: Effectiveness of occupational therapy services in mental health practice. Am J Occup Ther. 201 I; 65(3): 235-237.

3. Stucki G, Cieza A, Ewert T, Kostanjsek N, Chatterji S, ÜstÜn TB. Application of the International Classification of Functioning, Disability and Health (ICF) in clinical practice. Disability \& Rehabilitation, 2002;24(5): 28I-282.

4. Hendricks A. UN Convention on the Rights of Persons with Disabilities. Eur.J.Health L. 2007; |4:273.

5. American Psychiatric Association. The Diagnostic and Statistical Manual of Mental Disorders: DSM 5. Bookpoint US; 2013.

6. Creating Capable Teams Approach (CCTA): Best practice guidance to support new ways of working (NWW) and new roles. London: Department of Health; 2007.

7. Department of Health. Equity and excellence liberating the NHS. Crown; 2010.

8. Department of Health. The NHS outcomes framework 2011/12, Crown; 2010.

9. Department of Health. Payment by results in mental health: quality and outcome indicators.201 I [cited 2013 June 10]. Available from: https://www.gov.uk/government/publications/payment-by-resultsquality-and-outcomes-indicators 
10. Gutman SA. Why haven't we generated sufficient evidence? Part I: Building our evidence. Am J of Occup Ther, 2009; 63(4):383-385.

11. National Planning Commission. National Development Plan: Vision for 2030. 201 I. [cited 2013 Sep 16]. Available from: http//www. npconline.co.za

12. Subedar H. Provincial guidelines for the implementation of the three streams of the PHC re engineering. Guideline. Pretoria: Department of Health, 20I I: 10.

13. World Health Organization. Mental Health Atlas. Geneva: World Health Organization, 2005

14. Bateman C. Dismal use of legal safety net for mental health patients. S Afr Med J, 20I2; 102 (2): 68-70.

15. Pattison, M. (2008) Creating our own destiny, $\mathrm{Br} /$ Occup Ther, 7I (I0), 405.

16. Bannigan K, Lewis P, Laver-Fawcett A, Wolverson C, Long C, Cadman $D$, et al. Is it time for a mental health pathway in undergraduate programmes? Br |Occup Ther, 201 I; 74 (3): I53 - I56.

17. Creek J. An undergraduate mental health pathway (letter). $\mathrm{Br}$ Occup Ther, 20I I; 74(5): 257.

18. Khamisha $C$. An undergraduate mental health pathway: a Scottish perspective (letter). Br J Occup Ther, 201 I;74(7): 360-6I.

19. Neville D. A mental health pathway (letter). Br J Occup Ther, 20I I; 74(4): 204.

20. Creek J. Communicating the nature and purpose of occupational therapy. Occupational therapy: new perspectives. London: Whurr 1998:I|4-14I.

2I. Lloyd C, Kanowski H, Maas F. Occupational therapy in mental health: challenges and opportunities. Occup Ther Int, 20 I I;6 (2): I I0 - I I6.

22. Taylor A, Rubin R. How do occupational therapists define their role in a community mental health setting? $\mathrm{Br}$ | Occup Ther, I 999; 62 (2): $59-63$.

23. Parker $\mathrm{H}$. The role of occupational therapists in community mental health teams: generic or specialist? Br J Occup Ther, 200 I; 64 (I2): $609-6011$.

24. Greaves AJ, King R, Yellowlees P, Spence S, Lloyd C. The competence of mental health occupational therapists. $\mathrm{Br} \mid$ Occup Ther, 2002; 65(8): $381-386$

25. Wright $\mathrm{C}$, Rowe N. Protecting professional identity: service user involvement and occupational therapy. Br / Occup Ther. 2005; 68 (I): 45-47.

26. Pettican A, Bryant W. Sustaining a focus on occupation in community mental health practice. $\mathrm{Br} \mid$ Occup Ther, $2001 ; 70$ (4): I40 - I46.

27. Goren A. Occupational uncertainty and strictly defined areas of doubt and uncertainty. $\mathrm{Br}$ J Occup Ther, 200I; 65 (I0) $476-478$.

28. Krupa T, Clark C. Occupational therapy in the field of mental health: promoting occupational perspectives on health and wellbeing. Can Loccup Ther, 2004; 71 (2): 69 - 74.

29. Higgs J, Andresen L , Fish D. Practice knowledge - its nature, sources and contexts. In: Higgs J, Richardson B, Abrandt Dahlgren $M$, editors. Developing practice knowledge for health professionals. PLACE: Butterworth Heinemann, 2004: 5I-69.

30. Harries P, Gilhooly K. Generic and specialist occupational therapy casework in community mental health teams. $\mathrm{Br} /$ Occup Ther, 2003; 66 (3): 101 - 109.

3I. Hodgetts S, Hollis V, Triska O, Dennis S, Madill H, Taylor E. Occupational therapy students' and graduates' satisfaction with professional education and preparedness for practice. Can J Occup Ther, 2007; 74 (3): 148 - 160.

32. Duncan M, Alsop A. Practice and service learning in context. In: Lorennzo T, Duncan M, Buchanan $\mathrm{H}$ editors. Practice and service learning in Occupational Therapy: enhancing potential in context. London: Whurr; 2006: 7-19.

33. Lorenzo T. The right to rehabilitation: from policy development to implementation. S Afr J Occup Ther, 2010; 40 (I): I.

34. Doherty G, Stagnitti K, Schoo, AM. From student to therapist: Follow up of a first cohort of Bachelor of Occupational Therapy students. Aust Occup Ther J, 2009, 56: 34I-349.

35. Scheerer CR. Perceptions of effective professional behaviour feedback: occupational therapy students voices. Am J Occup Ther, 2003; 57: 205-2।4.

36. Lee S, Mackenzie L. Starting out in rural New South Wales: The experiences of new graduate occupational therapists. Australian
Journal of Rural Health, 2003; II: 36-43

37. Tryssenaar J, Perkins J. From student to therapist: exploring the first year of practice. Am J Occup Ther, 200I; 55 (I): 19-27.

38. Banks S, Bell E, Smits E. Integration tutorials and seminars: examining the integration of academic and fieldwork learning by student occupational therapists. Can J Occup Ther, 2000; 67: 93-100.

39. Atkinson K, Steward B. A longitudinal study of occupational therapy new practitioners in their first years of professional practice: preliminary findings. Br J Occup Ther, 1997; 60 (8): 338-342.

40. Simons H. Case Study Research in Practice. London: Sage, 2009.

4I. Stake ER. The art of case study research. London: Sage, 1995.

42. Gergen KJ. Knowledge as socially constructed. In: Gergen M, Gergen KJ, editors. Social Construction: A reader. London: Sage, 2003: 15-17.

43. Braun V, Clarke V. Using thematic analysis in psychology. Qualitative Research in Psychology, 2006; 3 (2): 77-101.

44. Tryssenaar J. The lived experience of becoming an occupational therapist. 1999; $\mathrm{Br}$ J Occup Ther, 62 (3): 208-2I I.

45. Seah $\mathrm{CH}$, Mackenzie L, Gamble J. Transition of graduates of the master of Occupational Therapy to practice. Aust Occup Ther J, 201 I; 58:103-110.

46. Barnett R. Knowing and becoming in the higher education curriculum. Studies in Higher Education, 2009; 34 (4): 429 - 440.

47. Duncan M, McMillan J. Practice and service learning in context. In: Lorenzo T, Duncan M, Buchanan $\mathrm{H}$ et al, editors. Practice and service learning in Occupational Therapy: enhancing potential in context. London: Whurr, 2006: 20-35.

48. Kronenberg F, Pollard N, Sakellariou D. Occupational Therapies without Borders - volume 2: towards an ecology of occupationbased practices. Edinburgh: Churchill Livingstone Elsevier, $20 \mathrm{II}$.

49. Whiteford GE, Hocking C. Occupational science: society, inclusion, participation. Oxford, United Kingdom: Wiley-Blackwell, $201 \mathrm{I}$.

50. Savin-Baden M. From cognitive capability to social reform? Shifting perceptions of learning in immersive virtual worlds. Research in Learning Technology, 2008;16 (3): I5I-I6I.

5I. Savin-Baden M. Learning Spaces: Creating opportunities for Knowledge Creation in Academic Life. Maidenhead: McGraw Hill International, 2008.

\section{Corresponding Author}

Katherine Wimpenny

DMLL, Coventry University, UK

Priory Street

Coventry University, UK

CVI 5FB

k.wimpenny@coventry.ac.uk 